\title{
Dynamic Phasor Modelling of LCC-HVDC System Based on a Practical Project
}

\author{
Huan $\mathrm{LI}^{1 *}$ and Kang QIN ${ }^{1}$ \\ ${ }^{1}$ Electrical Power Research Institute, CSG, State Key Laboratory of HVDC. Guangzhou, China
}

\begin{abstract}
This paper presents a detailed dynamic phasor modeling process of a line-commutated converter-based HVDC (LCC-HVDC) system. Firstly, the dynamic phasor models of the single-ended LCC rectifier station, inverter station and the DC line are established, respectively. Secondly, LCC-HVDC is an ACDC-AC system. The interfaces are explained to connect the converter stations with the DC line. Through block modeling, it is helpful to simplify the process and verify the accuracy of each block. Finally, based on a practical project, the model is compared with the electromagnetic-transient (EMT) simulation results in PSCAD/EMTDC to verify the accuracy of the dynamic phasor model.
\end{abstract}

\section{Introduction}

Because the line-commutated converter-based HVDC (LCC-HVDC) project has the advantage of long-distance and large-capacity transmission, it is widely used in the world. However, the transmission capacity of the LCCHVDC project increases continuously, so that the strength of the AC system at the receiving end weakens relatively[1]. Besides, with a number of LCC-HVDC putting into operation, the coupling between the receiving and the sending end is getting closer[2]. Therefore, it is urgent to study the stability of the AC and DC hybrid power system.

As a key device for connecting AC and DC systems, LCC converters have very complex nonlinear characteristics. It is not only difficult to study them directly, but also not conducive to explore the stability mechanism [3]-[4]. Therefore, developing the linearization model in time-domain or frequency-domain is a basic and important method to analyze the stability.

Reference [5]-[7] develop a time-domain linearization model based on the quasi-steady-state characteristics of the LCC converter. Reference [8] presents an averagevalue model for a LCC-HVDC system using dynamic phasors. Compared with electromagnetic-transient (EMT) model, the average-value model reduces unnecessary computational complexity when the high-frequency dynamics of the system are not concerned. Reference [9][10] develop a small-signal model of the LCC inverter to investigate the impact of the control system on stability. By using the switching function, the relationship of the voltage and current of AC and DC side are described. However, it only aims at the single side modeling including the LCC inverter station, AC system and control system. Although many scholars have researched on small-signal modeling of LCC-HVDC, there is almost no literature on explaining the idea of simplifying the modeling process of a complex LCC-HVDC system.

In this paper, the idea of block modeling is adopted. First, the LCC-HVDC system is divided into three subsystems including the LCC rectifier side, the LCC inverter side and the DC line. Second, the dynamic phasor models of three sub-systems are established, independently. Third, the three sub-systems are connected through the interfaces. Finally, a dynamic phasor model of LCC-HVDC is established and validated by the dynamic model in MATLAB and the EMT simulation from PSCAD/EMTDC. The results show the accuracy of the dynamic phasor model of LCC-HVDC based on a practical project.

\section{Study system}

\subsection{Description of the study system}

The study system is a unipolar 12-pulse LCC-HVDC system, shown in figure 1 . The rectifier station and the inverter station are connected by the DC line. On the rectifier side, the $\mathrm{AC}$ system is connected to the rectifier by transformers. AC filter banks and reactive power compensation devices are also connected at the point of common coupling (PCC) to filter out harmonics and compensate reactive power. The DC side of the rectifier is connected to the DC line through the smoothing reactor. The system structure is symmetric, therefore, the same devices and connections are also available on the inverter side.

As for the control system, the phase-locked loop (PLL) locks the phase of the PCC voltage to provide a phase basis for the synchronization of the LCC-HVDC. The fixed current controller and the fixed voltage controller are adopted by the rectifier and inverter, respec-

*Corresponding author's e-mail: lihuan3@csg.cn 
tively. $I_{\text {dref }}$ and $U_{\text {dref }}$ are the reference current and voltage. $I_{\mathrm{dm}_{-} \mathrm{r}}$ and $U_{\mathrm{dm}_{-} \mathrm{i}}$ can be obtained by the $I_{\mathrm{d}_{-} \mathrm{r}}$ and $U_{\mathrm{d}_{-} \mathrm{i}}$ through the measurement. The command value output by

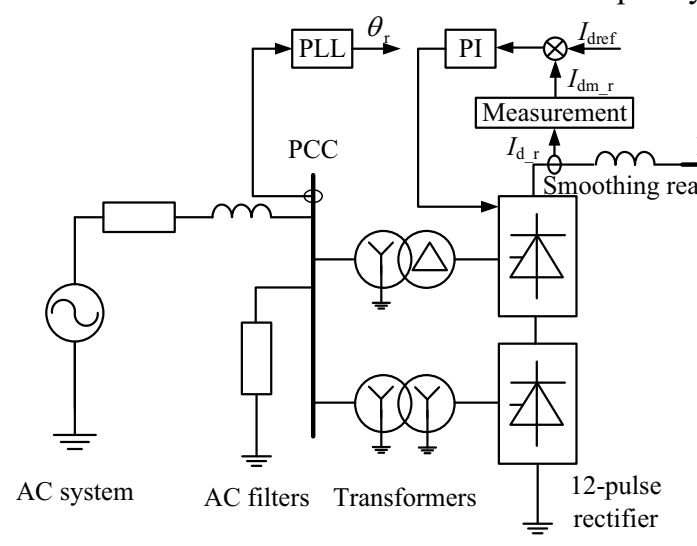

the controllers are the delay trigger angle $\left(\alpha_{\mathrm{r}}\right)$ of the rectifier and the advance trigger angle $\left(\beta_{\mathrm{i}}\right)$ of the inverter.

Figure 1. The configuration of LCC-HVDC system.

\subsection{The interfaces of subsystems}

by the smoothing reactors. The equivalent circuit of the rectifier and inverter subsystems are shown in figure 2 .

In order to simplify modelling, the LCC-HVDC system can be divided into three subsystems, which are bounded

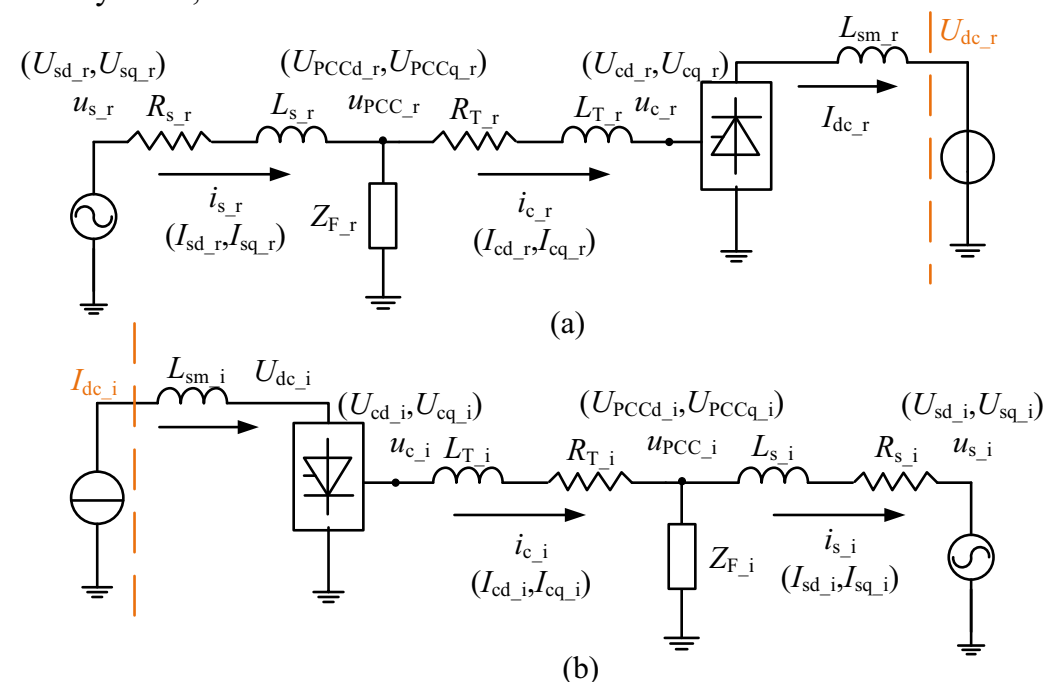

Figure 2. The equivalent circuit: (a) the rectifier subsystem; (b) the inverter subsystem.

In figure 2(a), the subscript $r$ represents all the variables on the rectifier side. Correspondingly, the variables on the inverter side are represented by the subscript $i$, shown in figure $2(\mathrm{~b}), u_{\mathrm{s} \mathrm{r}}$ and $i_{\mathrm{s} \mathrm{r}}$ are the voltage and current of the AC system, respectively. The impedance of AC system consists of $R_{\mathrm{S}_{-} \mathrm{r}}$ and $L_{\mathrm{s}_{-} \mathrm{r}}$, which are in series. $u_{\text {PCC }} r$ is the voltage of PCC. $Z_{\mathrm{F}_{-} r}$ is the impedance of the AC filters. $R_{\mathrm{T}_{-} \mathrm{r}}$ and $L_{\mathrm{T}_{-} \mathrm{r}}$ represent the impedance of the transformer. $u_{\mathrm{c}_{-} \mathrm{r}}$ and $i_{\mathrm{c}_{-} \mathrm{r}}$ are the voltage and current on AC side of the rectifier, respectively. $L_{\mathrm{sm}_{-} \mathrm{r}}$ is the smooth- ing reactor. $U_{\mathrm{dc} \_\mathrm{r}}$ and $I_{\mathrm{dc} \_}$are the DC voltage and current, respectively.

Due to the fixed voltage controller on the inverter side, $U_{\mathrm{dc} \_\mathrm{r}}$ can be substituted by a DC voltage source. Similarly, $I_{\mathrm{dc} \text { r }}$ can be substituted by a DC current source for the fixed current controller on the inverter side. The variables in brackets are obtained by $\mathrm{d}-\mathrm{q}$ transformation of the corresponding electrical quantities.

The DC line adopts the T-type equivalent circuit, shown in figure 3 .

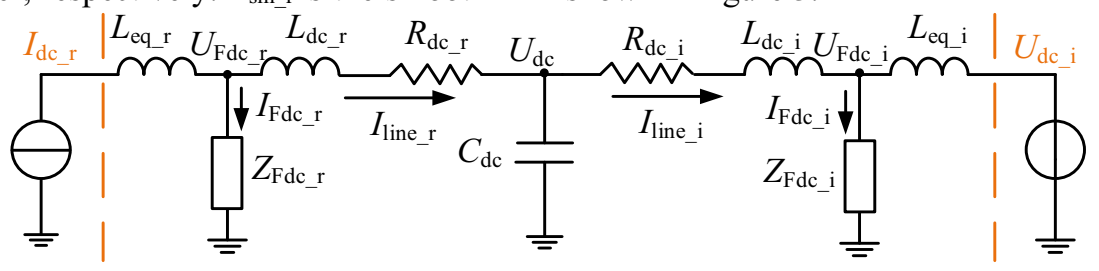

Figure 3. The T-type equivalent circuit of the DC line. 
In which, $R_{\mathrm{dc} \_1}, R_{\mathrm{dc} \_2}, L_{\mathrm{dc} \_1}$ and $L_{\mathrm{dc} \_2}$ are the resistances and reactors of the DC line. $C_{\mathrm{dc}}$ is the ground capacitance. $Z_{\mathrm{Fdc} \text { r }}$ represents the impedance of the DC filter banks on the rectifier side, which is the same as $Z_{\mathrm{Fdc} \text { i }}$ on the inverter side. $I_{\mathrm{dc}_{-} \mathrm{r}}$ and $U_{\mathrm{dc} \_\mathrm{i}}$ are the interfaces to connect the rectifier and inverter. The commutation inductor of the transformer $\left(L_{\text {eq }}\right.$ ) should be considered on the DC side because the fixed current control on the rectifier side cannot keep the current unchanged 11. $L_{\text {eq }}$ i on the inverter side is similar. $L_{\text {eq }} \mathrm{r}$ can be expressed as

$$
L_{\text {eq_ }}=2 \times\left(2-\frac{3 \mu}{2 \pi}\right) L_{\mathrm{T}_{-} \mathrm{r}}
$$

In which, $\mu$ is commutation overlap angle. $L_{\mathrm{T}_{-} \mathrm{r}}$ is the leakage inductor of the transformer.

\section{Dynamic phasor modelling of LCC- HVDC system}

\subsection{Modelling on the rectifier/inverter side}

\subsubsection{The AC system.}

The AC system model on both sides are the same except the current direction. Based on figure 2(a), the statespace representation of the $\mathrm{AC}$ system is

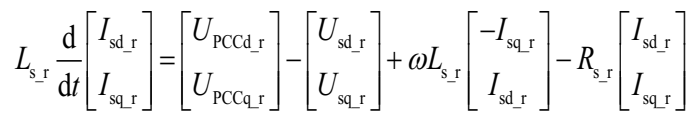

The voltage of the AC system and its d-q variables can be represented by

$$
\begin{gathered}
u_{\mathrm{s} \_\mathrm{r}}=V_{\mathrm{m}_{-} \mathrm{r}} \cos \left(\omega_{0} t+\alpha_{0 \_\mathrm{r}}\right) \\
\left\{\begin{array}{l}
U_{\mathrm{sd} \_\mathrm{r}}=V_{\mathrm{m}_{-} \mathrm{r}} \cos \left[\theta_{\mathrm{PLL} \_\mathrm{r}}-\left(\omega_{0} t+\alpha_{0 \_\mathrm{r}}\right)\right] \\
U_{\mathrm{sq} \_\mathrm{r}}=V_{\mathrm{m}_{-\mathrm{r}}} \sin \left[\left(\omega_{0} t+\alpha_{0 \_\mathrm{r}}\right)-\theta_{\mathrm{PLL}_{-} \mathrm{r}}\right]
\end{array}\right.
\end{gathered}
$$

In which, $V_{\mathrm{m}-\mathrm{r}}, \omega_{0}$ and $\alpha_{0} \mathrm{r}$ are the peak to peak voltage, angular frequency and phasor of the AC system. The state variable of the AC system on both side are

$$
\boldsymbol{X}_{\mathrm{AC}}=\left[U_{\mathrm{PCCd} \_\mathrm{r}}, U_{\mathrm{PCCq} \_}, I_{\mathrm{Sd} \_\mathrm{r}}, I_{\mathrm{Sq} \_\mathrm{r}}, U_{\mathrm{PCCd} \_\mathrm{i}}, U_{\mathrm{PCCq} \_\mathrm{i}}, I_{\mathrm{Sd} \_\mathrm{i}}, I_{\mathrm{Sq} \_\mathrm{i}}\right]
$$

\subsubsection{The AC filter banks on the rectifier/inverter side.}

According to the practical project, the configuration of the $\mathrm{AC}$ filter banks on the rectifier and inverter side are shown in figure 4 .

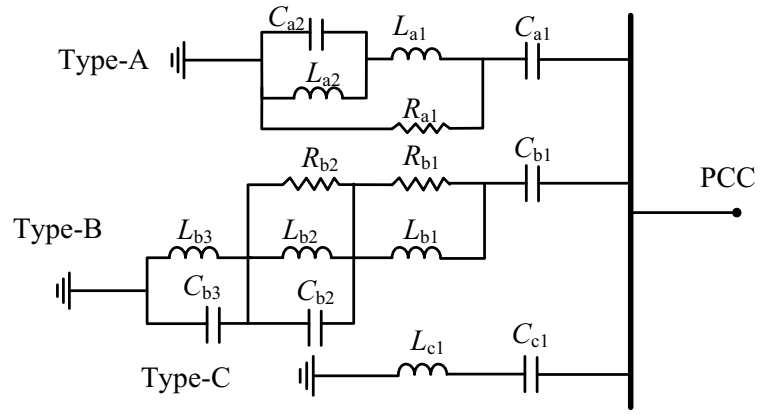

(a)

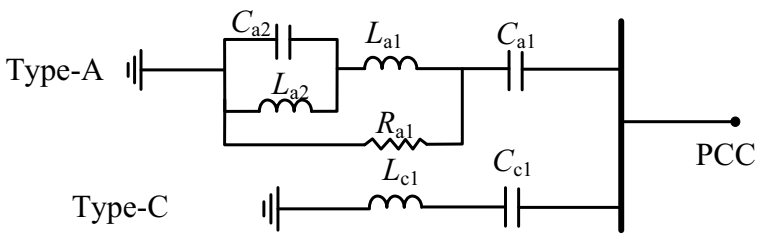

(b)

Figure 4. The configuration of the AC filter banks: (a) the rectifier side; (b) the inverter side.

According to the configuration of the filter banks, they can be divided into three groups as A, B and C. The state-space equation of the AC filters on the rectifier side can be obtained by Kirchhoff's laws as

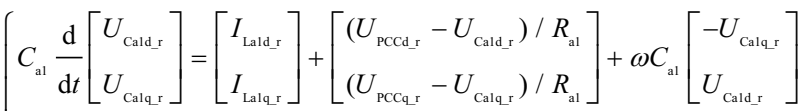

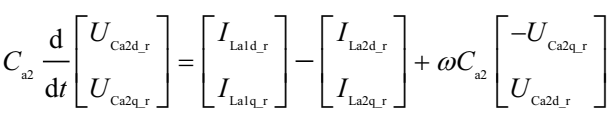

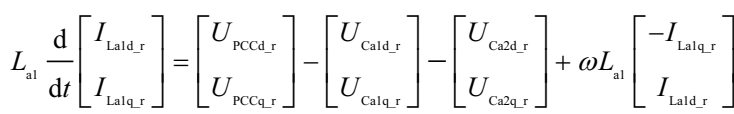

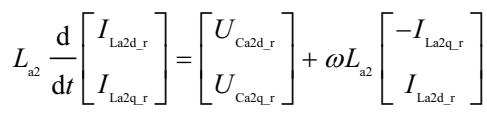




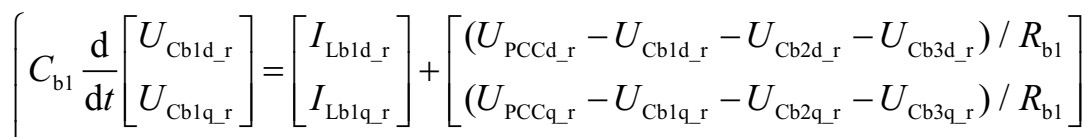

$$
\begin{aligned}
& +\omega C_{\mathrm{b} 1}\left[\begin{array}{l}
-U_{\mathrm{Cblq} \_\mathrm{r}} \\
U_{\mathrm{Cbld} \_\mathrm{r}}
\end{array}\right]
\end{aligned}
$$

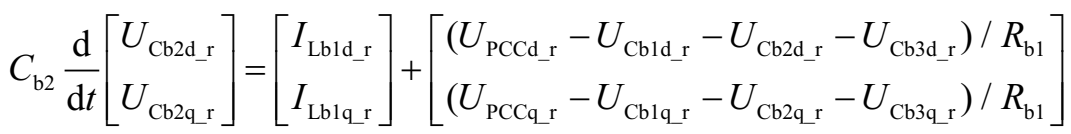

$$
\begin{aligned}
& -\left[\begin{array}{c}
I_{\mathrm{Lb2d} \_\mathrm{r}} \\
I_{\text {Lb2q } \mathrm{r}}
\end{array}\right]-\left[\begin{array}{l}
U_{\mathrm{Cb2d} \_\mathrm{r}} / R_{\mathrm{b} 2} \\
U_{\mathrm{Cb} 2 \mathrm{q} \_\mathrm{r}} / R_{\mathrm{b} 2}
\end{array}\right]+\omega C_{\mathrm{b} 2}\left[\begin{array}{l}
-U_{\mathrm{Cb2q} \_\mathrm{r}} \\
U_{\mathrm{Cb2d \_ r}}
\end{array}\right]
\end{aligned}
$$

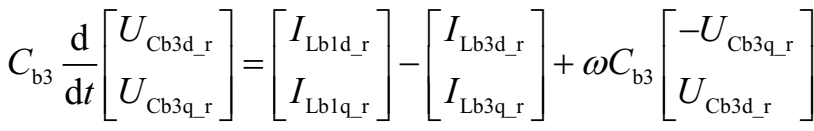

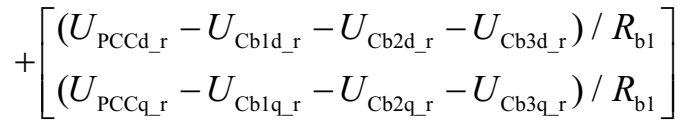

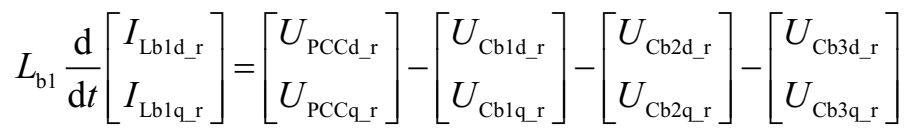

$$
\begin{aligned}
& +\omega L_{\mathrm{b} 1}\left[\begin{array}{c}
-I_{\text {Lblq_r }} \\
I_{\text {Lbld_r }}
\end{array}\right]
\end{aligned}
$$

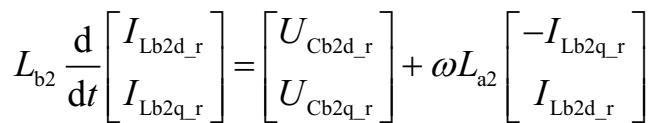

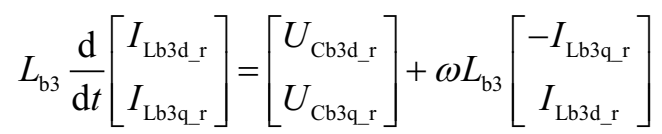

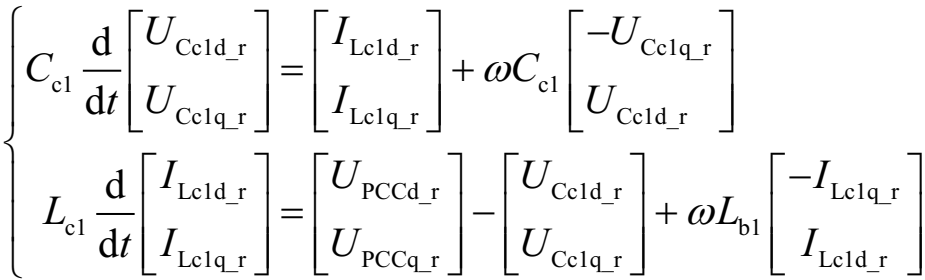

Similarly, the state-space equation of the AC filters on the inverter side are the equation (7) and (8), as long as change the subscript $r$ to $i$. The state variables are the voltage of capacitors and the current of inductors.

The state variable of the AC filter banks on both side are

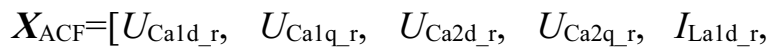
$I_{\text {La1q_r }}, I_{\text {La2d_r }}, I_{\text {La2q_r }}, U_{\text {Cb1d_r }}, U_{\mathrm{Cb1q} \_\mathrm{r}}, U_{\mathrm{Cb} 2 \mathrm{~d} \_\mathrm{r}}, U_{\mathrm{Cb} 2 \mathrm{q} \_\mathrm{r}}$, $U_{\text {Cb3d_r }}, U_{\text {Cb3q_r }}, I_{\text {Lb1d_r }}, I_{\text {Lb1q_r }}, I_{\text {Lb2d_r }}, I_{\text {Lb2q_r }}, I_{\text {Lb3d_r }}$, $I_{\text {Lb3q_r }}, U_{\text {Ccld_r }}, U_{\text {Cclq_r }}, I_{\text {Lcld_r }}, I_{\text {Lclq } \_r}, U_{\text {Cald_i }}, U_{\text {Calq } \_ \text {i }}$, $U_{\text {Ca2d_i }}, U_{\text {Ca2q_i }}, I_{\text {Lald_i }}, I_{\text {La1q_i }}, I_{\text {La2d_i }}, I_{\text {La2q_i }}, U_{\text {Ccld_i }}$, $\left.U_{\mathrm{Cclq}_{\perp} \mathrm{i}}, I_{\mathrm{Lcld} \_\mathrm{i}}, I_{\mathrm{Lclq}} \mathrm{i}\right]$

\subsubsection{The rectifier / inverter.}

The main task of the converter is AC-DC conversion. The relationship between $\mathrm{AC}$ and $\mathrm{DC}$ voltage and current can be described as

$$
\begin{gathered}
\left\{\begin{array}{l}
i_{\mathrm{ca} \_\mathrm{r}}=I_{\mathrm{dc} \_\mathrm{r}} S_{\mathrm{ai}} \\
i_{\mathrm{cb} \_\mathrm{r}}=I_{\mathrm{dc} \_\mathrm{r}} S_{\mathrm{bi}} \\
i_{\mathrm{cc} \_\mathrm{r}}=I_{\mathrm{dc} \_\mathrm{r}} S_{\mathrm{ci}}
\end{array}\right. \\
U_{\mathrm{dc} \_\mathrm{r}}=u_{\mathrm{ca}} S_{\mathrm{au}}+u_{\mathrm{cb}} S_{\mathrm{bu}}+u_{\mathrm{cc}} S_{\mathrm{cu}}
\end{gathered}
$$

In which, $S_{\mathrm{abci}}\left(S_{\mathrm{ai}}, S_{\mathrm{bi}}, S_{\mathrm{ci}}\right)$ and $S_{\mathrm{abcu}}\left(S_{\mathrm{au}}, S_{\mathrm{bu}}, S_{\mathrm{cu}}\right)$ are the switching functions of current and voltage 12 , which are 


$$
\left\{\begin{array}{l}
S_{\mathrm{a}, \mathrm{ui}}=A_{\mathrm{u} / \mathrm{i}} \cos (\omega t \pm \varphi) \\
S_{\mathrm{b}, \mathrm{u} / \mathrm{i}}=A_{\mathrm{u} / \mathrm{i}} \cos \left(\omega t \pm \varphi-\frac{2}{3} \pi\right) \\
S_{\mathrm{c}, \mathrm{ui}}=A_{\mathrm{u} / \mathrm{i}} \cos \left(\omega t \pm \varphi+\frac{2}{3} \pi\right)
\end{array}\right.
$$

$\varphi$ is the angle of power factor, in front of which the plus is for the inverter and the minus is for the rectifier. Taking the commutation of the LCC into account, $A_{\mathrm{u} / \mathrm{i}}$ is a coefficient to correct the voltage/current.

Define

$$
\left\{\begin{array}{l}
A_{\mathrm{u}}=\frac{2 \sqrt{3}}{\pi} \cos \left(\frac{\mu}{2}\right) \\
A_{\mathrm{i}}=\frac{2 \sqrt{3}}{\pi} \frac{\sin \left(\frac{\mu}{2}\right)}{\frac{\mu}{2}}
\end{array}\right.
$$

The current of the AC side of the rectifier $\left(i_{\mathrm{c}_{-} \mathrm{r}}\right)$ can be calculated by equation (10), (11), (12). $I_{\mathrm{cd}_{-} \mathrm{r}}$ and $I_{\mathrm{cq} \_\mathrm{r}}$ are the results of $d-q$ transformation as

$$
\left\{\begin{array}{l}
I_{\mathrm{cd} \_\mathrm{r}}=2 I_{\mathrm{dc} \_\mathrm{r}} A_{\mathrm{i}} \cos ( \pm \varphi) \\
I_{\mathrm{cq} \_\mathrm{r}}=-2 I_{\mathrm{dc} \_\mathrm{r}} A_{\mathrm{i}} \sin ( \pm \varphi)
\end{array}\right.
$$

In which, the plus is for the inverter and the minus is for the rectifier.

\subsubsection{The PLL.}

The control block diagram of PLL on the rectifier side is shown in figure 5 .

$\mu$ is the commutation overlap angle.

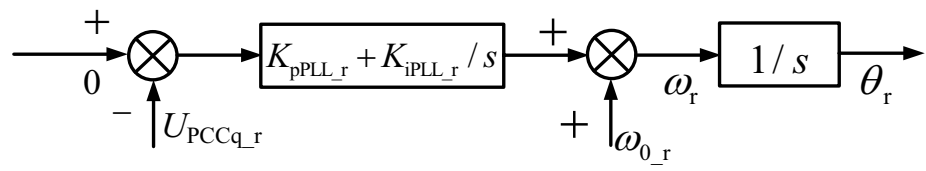

Figure 5. The control block diagram of PLL on the rectifier side.

The state-space equation can be expressed as

$$
\left\{\begin{array}{l}
\frac{\mathrm{d} \theta_{\mathrm{r}}}{\mathrm{d} t}=\omega_{\mathrm{r}} \\
\frac{\mathrm{d} \omega_{\mathrm{r}}}{\mathrm{d} t}=-K_{\mathrm{pPLL}_{-} \mathrm{r}} \frac{\mathrm{d} U_{\mathrm{PCCq} \mathrm{r}}}{\mathrm{d} t}-K_{\mathrm{iPLL} \__{-}} U_{\mathrm{PCCQ} \_\mathrm{r}}
\end{array}\right.
$$

In which, $\omega_{\mathrm{r}}$ and $\theta_{\mathrm{r}}$ are the angular frequency and phase of the output of PLL. $K_{\text {pPLL_r }}$ and $K_{\text {PLL_r }}$ are the proportion and the integral gain, respectively.

The state space equation of PLL on the inverter side is the same as equation (14), except for changing the subscript $r$ to $i$.

The state variable of the PLL on both side are

$$
\boldsymbol{X}_{\mathrm{PLL}}=\left[\theta_{\mathrm{r}}, \omega_{\mathrm{r}}, \theta_{\mathrm{i}}, \omega_{\mathrm{i}}\right]
$$

\subsubsection{The control system}

The fixed current control and the fixed voltage control block diagram on each side are shown in figure 6 .

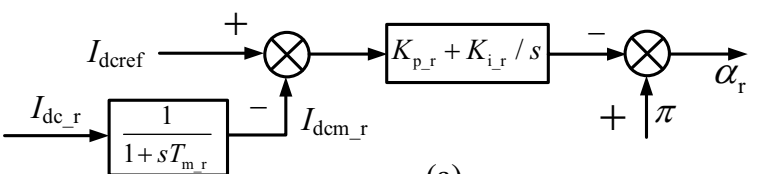

(a)

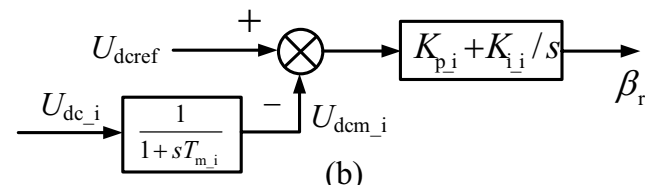

(b)

Figure 6. The block diagram: (a) the fixed current control on the rectifier side; (b) the fixed voltage control on the inverter side.
The state-space equation based on figure 6(a) can be expressed as

$$
\left\{\begin{array}{l}
\frac{\mathrm{d} x_{1 \_\mathrm{r}}}{\mathrm{d} t}=I_{\mathrm{dcref}}-I_{\mathrm{dcm} \_\mathrm{r}} \\
\pi-\alpha_{\mathrm{r}}=K_{\mathrm{p} \_\mathrm{r}} \cdot \frac{\mathrm{d} x_{1 \_\mathrm{r}}}{\mathrm{d} t}+K_{\mathrm{i}_{-} \mathrm{r}} \cdot x_{1 \_\mathrm{r}}
\end{array}\right.
$$

$K_{\mathrm{p}_{-} \mathrm{r}}$ and $K_{\mathrm{i}_{\mathrm{r}} \mathrm{r}}$ are the proportion and the integral gain, respectively. $x_{1-r}$ is the difference between the reference current $\left(I_{\mathrm{dcref}}\right)$ and the measured current $\left(I_{\mathrm{dcm} \_}\right)$, which is a state variable. Adopting the first order inertia element to measure the DC current on the rectifier side $\left(I_{\mathrm{dc} \_} \mathrm{r}\right)$, the measured current $\left(I_{\mathrm{dcm} \_} \mathrm{r}\right)$ can be obtained by

$$
T_{\mathrm{m} \_\mathrm{r}} \frac{\mathrm{d} I_{\mathrm{dcm} \_\mathrm{r}}}{\mathrm{d} t}=I_{\mathrm{dc} \_\mathrm{r}}-I_{\mathrm{dcm} \_\mathrm{r}}
$$

$T_{\mathrm{m}_{-}} \mathrm{r}$ is the time constant of the first order inertia element.

Similarly, the state-space equation based on figure 6(b) can be expressed as

$$
\begin{aligned}
& \left\{\begin{array}{l}
\frac{\mathrm{d} x_{1 \_\mathrm{i}}}{\mathrm{d} t}=U_{\mathrm{dcm} \_\mathrm{i}}-U_{\mathrm{dcref}} \\
\beta_{\mathrm{i}}=K_{\mathrm{p}_{-} \mathrm{i}} \frac{\mathrm{d} x_{1 \_i}}{\mathrm{~d} t}+K_{\mathrm{i}_{-} \mathrm{i}} x_{1 \_\mathrm{i}}
\end{array}\right. \\
& T_{\mathrm{m}_{-} \mathrm{i}} \frac{\mathrm{d} U_{\mathrm{dcm} \_\mathrm{i}}}{\mathrm{d} t}=U_{\mathrm{dc} \_\mathrm{i}}-U_{\mathrm{dcm} \_\mathrm{i}}
\end{aligned}
$$

$K_{\mathrm{p}_{-} \mathrm{i}}$ and $K_{\mathrm{i}_{-} \mathrm{i}}$ are the proportion and the integral gain, respectively. $x_{1_{-} \mathrm{i}}$ is the difference between the reference voltage $\left(U_{\text {dcref }}\right)$ and the measured voltage $\left(U_{\mathrm{dcm}_{-} \mathrm{r}}\right)$, which is a state variable. $T_{\mathrm{m}_{\mathrm{i}}}$ is the time constant. 
The state variable of the control system on both side are

$$
\boldsymbol{X}_{\mathrm{Ctl}}=\left[x_{1 \_} \mathrm{r}, I_{\mathrm{dcm} \_} \mathrm{r}, x_{1 \_\mathrm{i}}, U_{\mathrm{dcm} \_} \mathrm{r}\right]
$$

\subsection{Modelling of the DC line}

According to the T-type equivalent circuit in figure 3, the state-space equations of the DC line are

$$
\left\{\begin{array}{l}
L_{\mathrm{dc} \_\mathrm{r}} \frac{\mathrm{d} I_{\text {line_ } \mathrm{r}}}{\mathrm{d} t}=U_{\mathrm{Fdc} \_\mathrm{r}}-U_{\mathrm{dc}}-R_{\mathrm{dc \_} \_\mathrm{I}} I_{\text {line_ } \mathrm{r}} \\
C_{\mathrm{dc}} \frac{\mathrm{d} U_{\mathrm{dc}}}{\mathrm{d} t}=I_{\text {line_ } \mathrm{r}}-I_{\text {line } \_\mathrm{i}} \\
L_{\mathrm{dc} \_\mathrm{i}} \frac{\mathrm{d} I_{\text {line } \_\mathrm{i}}}{\mathrm{d} t}=U_{\mathrm{dc}}-U_{\mathrm{Fdc} \_\mathrm{i}}-R_{\mathrm{dc} \_ \text {i }} I_{\text {line_ } \mathrm{i}}
\end{array}\right.
$$

There are two banks of the DC filter, whose configuration is same. The DC filter bank on the rectifier side is shown in figure 7.

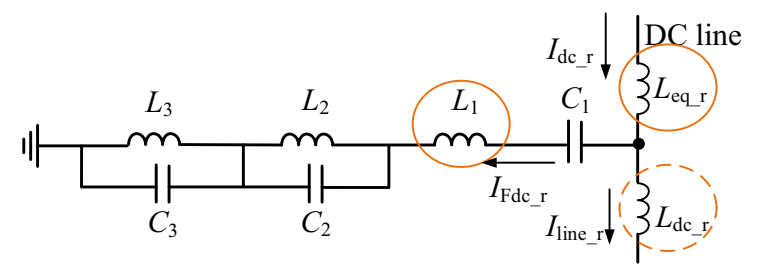

Figure 7. The configuration of the DC filter bank on the rectifier side.

It is important to note that the state variables including the capacitor voltage and inductor current must be independent. Thus, for the convenience of modelling, choose $I_{\mathrm{Fdc} \_\mathrm{r}}$ and $I_{\mathrm{dc} \_\mathrm{r}}$ as the state variables on the rectifier side and choose $I_{\mathrm{Fdc} \_}$and $I_{\text {line_r }}$ on the inverter side. The state-space equation of the DC filter banks can be obtained as

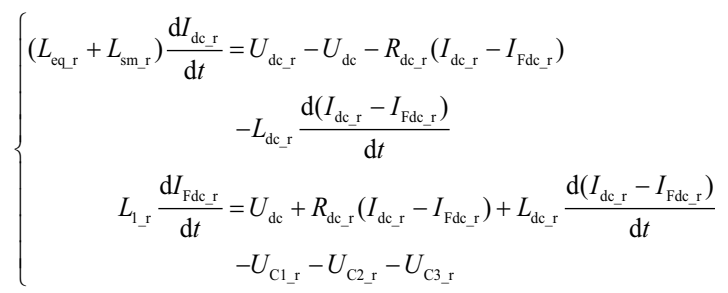

$$
\left\{\begin{array}{l}
L_{2 \_\mathrm{r}} \frac{\mathrm{d} I_{\mathrm{L} 2 \_\mathrm{r}}}{\mathrm{d} t}=U_{\mathrm{C}_{\_} \mathrm{r}} \\
L_{3 \_\mathrm{r}} \frac{\mathrm{d} I_{\mathrm{L} 3 \_\mathrm{r}}}{\mathrm{d} t}=U_{\mathrm{C} 3 \_\mathrm{r}} \\
C_{1 \_\mathrm{r}} \frac{\mathrm{d} U_{\mathrm{C} 1 \_\mathrm{r}}}{\mathrm{d} t}=I_{\mathrm{Fdc} \_\mathrm{r}} \\
C_{2 \_r \mathrm{r}} \frac{\mathrm{d} U_{\mathrm{C} 2 \_\mathrm{r}}}{\mathrm{d} t}=I_{\mathrm{Fdc} \_\mathrm{r}}-I_{\mathrm{L} 2 \_\mathrm{r}} \\
C_{3 \_\mathrm{r}} \frac{\mathrm{d} U_{\mathrm{C} 3 \_\mathrm{r}}}{\mathrm{d} t}=I_{\mathrm{Fdc} \_\mathrm{r}}-I_{\mathrm{L} 3 \_\mathrm{r}}
\end{array}\right.
$$

The state variable of the DC line and DC filter banks on both side are $\boldsymbol{X}_{\mathrm{DC}}=\left[I_{\mathrm{dc} \_}, U_{\mathrm{C} 1 \_\mathrm{r}}, U_{\mathrm{C}_{-} \text {r }}, U_{\mathrm{C}_{-} \mathrm{r}}, I_{\mathrm{L} 1 \_\mathrm{r}}, I_{\mathrm{L} 2 \_} \mathrm{r}\right.$,

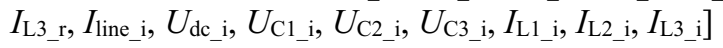

\subsection{Small-signal dynamic modelling of LCC- HVDC}

Based on the state-space model above, the small-signal dynamic model can be obtained by linearization as

$$
\frac{\mathrm{d} \Delta \boldsymbol{X}}{\mathrm{d} t}=\boldsymbol{A} \Delta \boldsymbol{X}+\boldsymbol{B} \Delta \boldsymbol{U}
$$

Based on the practical project, the order of LCCHVDC system is 67 . The state variable $\boldsymbol{X}$ consists of the AC system, the AC filter banks, the PLL, the control system, the DC line and the DC filter banks. The input variable $\boldsymbol{\Delta U}=\left[I_{\mathrm{dcref}}, U_{\mathrm{dcref}}\right]^{\mathrm{T}}$.

\section{Simulation Results and Model Valida- tion}

In this section, a dynamic phasor model for a practical LCC-HVDC system is developed in MATLAB/SIMULINK. In order to validate the accuracy of the dynamic phasor model, the time-domain response obtained from the model in MATLAB is compared with the detailed time-domain simulation in PSCAD/EMTDC.

\subsection{The parameters of the LCC-HVDC system}

The parameters of the practical LCC-HVDC system are shown in table I and table II.

Table 1. The main parameters of LCC-HVDC

\begin{tabular}{llll}
\hline The Group & Parameter Description & \multicolumn{2}{c}{ Value } \\
\cline { 3 - 4 } & & Rectifier & Inverter \\
\hline The rated value & DC current $(\mathrm{kA})$ & 3 & \\
& DC voltage $(\mathrm{kV})$ & 500 & 525 \\
& AC voltage $(\mathrm{kV})$ & 525 & 5.0 \\
\hline \multirow{2}{*}{ The AC system } & Short-circuit ratio & 5.0 & $85.23^{\circ}$ \\
& Impedance angle & $86.185^{\circ}$ & \\
\hline
\end{tabular}




\begin{tabular}{llll}
\hline & PCC voltage $(\mathrm{pu})$ & 1.0 & 1.0 \\
\hline The transformer & Leakage reactor $(\mathrm{pu})$ & 0.16 & 0.152 \\
& Capacity (MVA) & 889.5 & 833.4 \\
& Ratio of voltage & $525 / 209.7$ & $525 / 196.5$ \\
\hline The PLL & Proportion gain & 10 & 10 \\
& Integral gain & 50 & 50 \\
\hline The control & Proportion gain & 0.2 & 0.5 \\
system & Integral gain & 100 & 50 \\
& Time constant & 0.0012 & 0.02 \\
\hline \multirow{2}{*}{ The DC line } & Inductor $(\mathrm{mH})$ & 0.1979 & 0.1979 \\
& Resistor $(\Omega)$ & 5.2 & 5.2 \\
& Capacitor $(\mathrm{uF})$ & 39 & \\
& Smoothing inductor(mH) & 0.3 & 0.3 \\
\hline
\end{tabular}

Table 2. The parameters of filter banks and DC line

\begin{tabular}{|c|c|c|c|c|}
\hline \multirow[t]{2}{*}{ The Group } & \multirow{2}{*}{\multicolumn{2}{|c|}{ Parameter Description }} & \multicolumn{2}{|c|}{ Value } \\
\hline & & & Rectifier & Inverter \\
\hline \multirow{6}{*}{ The DC filter banks } & \multirow{3}{*}{ Capacitors (uF) } & $C_{1}$ & 1.6 & \\
\hline & & $C_{2}$ & 4.48 & \\
\hline & & $C_{3}$ & 5.81 & \\
\hline & \multirow{3}{*}{ Inductors (mH) } & $L_{1}$ & 10.869 & \\
\hline & & $L_{2}$ & 10.384 & \\
\hline & & $L_{3}$ & 20.6 & \\
\hline \multirow{5}{*}{ The AC filter banks (Type-A) } & \multirow{2}{*}{ Capacitors (uF) } & $C_{1 \mathrm{a}}$ & 1.605 & 1.963 \\
\hline & & $C_{2 a}$ & 56.824 & 3.709 \\
\hline & \multirow{2}{*}{ Inductors $(\mathrm{mH})$} & $L_{1 \mathrm{a}}$ & 44.731 & 17.01 \\
\hline & & $L_{2 \mathrm{a}}$ & 1.239 & 9.918 \\
\hline & Resistors $(\Omega)$ & $R_{1 \mathrm{a}}$ & 2500 & 500 \\
\hline \multirow[t]{8}{*}{ The AC filter banks (Type-B) } & \multirow{3}{*}{ Capacitors (uF) } & $C_{1 \mathrm{~b}}$ & 1.578 & / \\
\hline & & $C_{2 \mathrm{~b}}$ & 7.218 & \\
\hline & & $C_{3 \mathrm{~b}}$ & 7.704 & \\
\hline & \multirow{3}{*}{ Inductors (mH) } & $L_{1 \mathrm{~b}}$ & 8.116 & \\
\hline & & $L_{2 \mathrm{~b}}$ & 129.39 & l \\
\hline & & $L_{3 \mathrm{~b}}$ & 1.634 & \\
\hline & \multirow{2}{*}{ Resistors $(\Omega)$} & $R_{1 \mathrm{~b}}$ & 400 & l \\
\hline & & $R_{2 \mathrm{~b}}$ & 1500 & 1 \\
\hline \multirow[t]{2}{*}{ The AC filter banks (Type-C) } & Capacitors (uF) & $C_{1 \mathrm{c}}$ & 1.616 & 1.972 \\
\hline & Inductors $(\mathrm{mH})$ & $L_{1 \mathrm{c}}$ & 2.721 & 3.964 \\
\hline
\end{tabular}

It should be noted that the project parameters of the AC filter given in Table 2 are for the bipolar system, so they need to be converted.

\subsection{Results and analysis}

In order to investigate the step response of the system, two cases are set as follows:

Case 1: $U_{\text {dcref }}$ step changes from 0.93 p.u. to 0.90 p.u. at time $t=5 \mathrm{~s}$ and from $0.90 \mathrm{p}$.u. to $0.93 \mathrm{p}$.u. at time $t=8 \mathrm{~s}$.

Case 2: $I_{\text {dcref }}$ step changes from 1 p.u. to 0.95 p.u. at time $t=12 \mathrm{~s}$ and from 0.95 p.u. to 1 p.u. at time $t=15 \mathrm{~s}$.
In each case, the small-signal step responses of DC current, voltage of $\mathrm{PCC}$, active power on the rectifier side and DC voltage, voltage of PCC, active power on the inverter side are compared, completely. The comparison results are shown in figure 8 and 9.

It can be seen from the figures that the results of the dynamic phasor model in MATLAB have great consistency with the results of the detailed model in PSCAD. Besides, the simulation results in PSCAD has a larger range of fluctuation than the results in MATLAB, because all frequencies are included in the detailed model, but only fundamental frequency characteristics are considered in the dynamic phasor model in MATLAB. However, the average value of both is the same. 


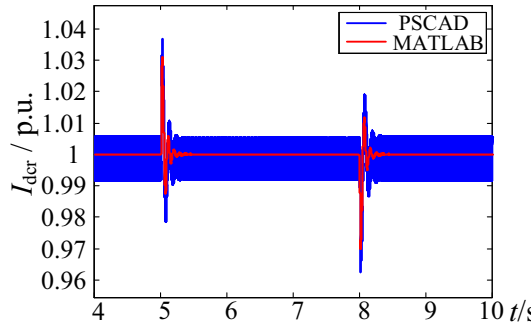

(a)

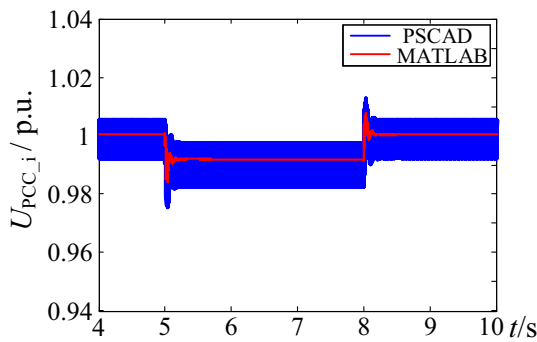

(c)

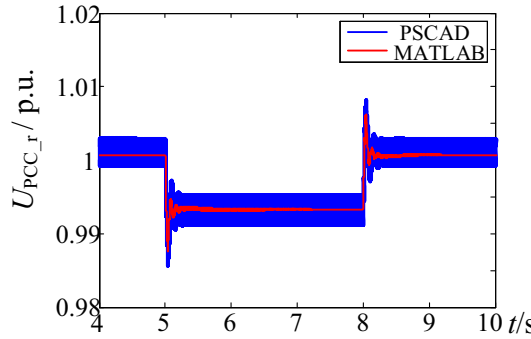

(e)

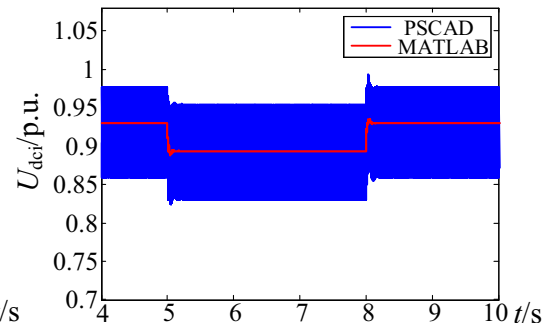

(b)

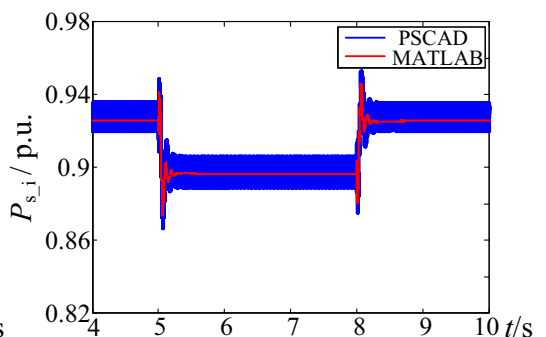

(d)

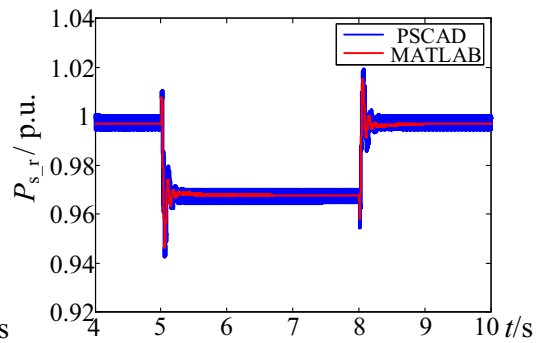

(f)

Figure 8. Validation case 1: (a) DC current on the rectifier side $I_{\mathrm{dcr}}$; (b) DC voltage on the inverter side $U_{\text {dci; }}$; (c) PCC voltage on the inverter side $U_{\mathrm{PCC}_{-}}$; (d) active power on the inverter side $P_{\mathrm{S}_{-}}$; (e) PCC voltage on the rectifier side $U_{\mathrm{PCC}_{-}}$; (d) active power on the rectifier side $P_{\mathrm{s}_{-} \text {. }}$.

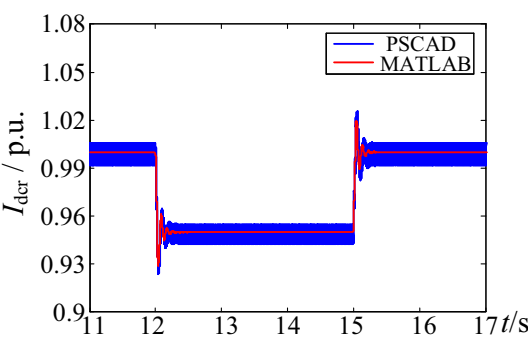

(a)

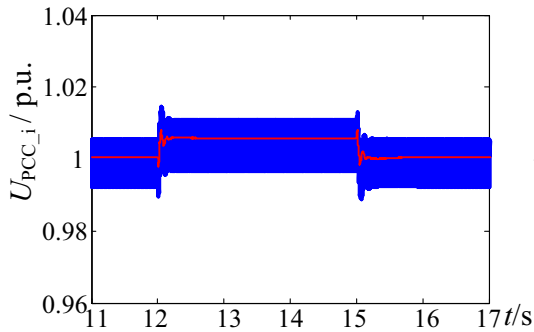

(c)

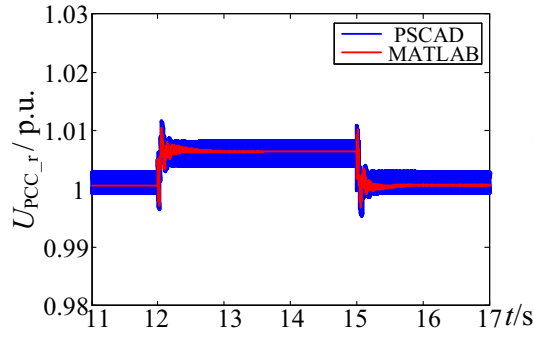

(e)

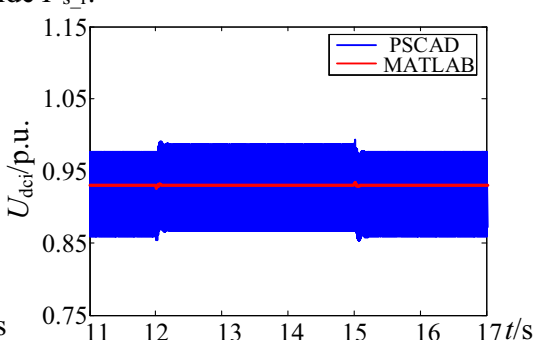

(b)

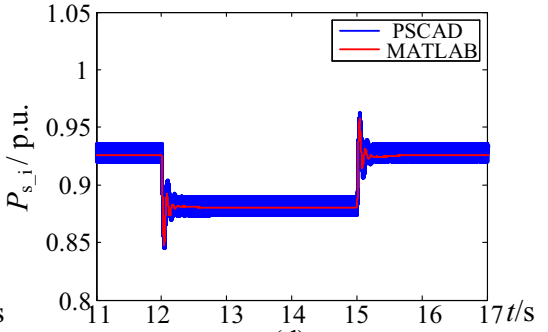

(d)

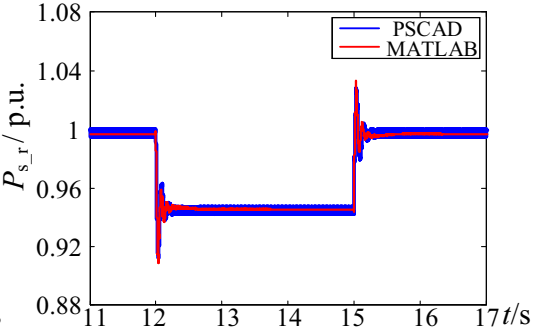

(f)

Figure 9. Validation case 2: (a) DC current on the rectifier side $I_{\mathrm{dcr}}$; (b) DC voltage on the inverter side $U_{\mathrm{dci}}$; (c) PCC voltage on the inverter side $U_{\mathrm{PCC}_{-}}$; (d) active power on the inverter side $P_{\mathrm{S}_{-}}$; (e) PCC voltage on the rectifier side $U_{\mathrm{PCC}_{-}}$; (d) active power on the rectifier side $P_{\mathrm{s} r}$. 


\section{Conclusion}

This paper presents a detailed dynamic phasor modeling process of a complex double-ended LCC-HVDC system. Through the idea of block modeling, it is helpful to simplify the process and verify the accuracy of each block. The blocks can be connected by the reserved interfaces. Besides, a practical project is provided. Based on the practical project, the accuracy of the dynamic phasor model is verified.

\section{Acknowledgments}

This work was financially supported by China Southern Power Grid Science and Technology Projects (ZBKJXM20190056).

\section{References}

1. Xue, Y., Zhang, X., Yang, C. (2016) Elimination of Commutation Failures of LCC HVDC System with Controllable Capacitors. IEEE Transactions on Power Systems. 31, 4: 3289-3299.

2. Zhao, W., Li, S., Qin L., Huang, Y. (2015) The stability study and simulation analysis on multi-infeed AC-DC hybrid power system. 5th International Conference on Electric Utility Deregulation and Restructuring and Power Technologies. Changsha. pp. 557562.

3. Li, Z., Shahidehpour, M. (2019) Small-Signal Modeling and Stability Analysis of Hybrid AC/DC Microgrids. IEEE Transactions on Smart Grid.10, 2: 2080-2095.

4. Zheng, A., Guo, C., Cui, P., Jiang, W., Zhao, C. (2019) Comparative Study on Small-Signal Stability of LCC-HVDC System With Different Control Strategies at the Inverter Station. IEEE Access. 7: 34946-34953.

5. Jovcic, D., Pahalawaththa, N., Zavahir, M. (1999) Analytical modelling of HVDC-HVAC systems. IEEE Transactions on Power Delivery.14, 2: 506511.

6. Jovcic, D., Pahalawaththa, N., Zavahir, M. (1999) Small signal analysis of HVDC-HVAC interactions. IEEE Transactions on Power Delivery. 14, 2: 525530.

7. Karawita, C., Annakkage, UD. (2009) Multi-infeed HVDC interaction studies using small-signal stability assessment. IEEE Transactions on Power Delivery. 24, 2: 910-918.

8. Daryabak, M. (2014) Modeling of LCC-HVDC Systems Using Dynamic Phasors. IEEE Transactions on Power Delivery. 29, 4: 1989-1998.

9. Guo, C., Ning, L., Wang, H. (2017) Switchingfunction based dynamic model of LCC-HVDC station and small signal stability analysis. Power System Technology. 41, 12: 3862-3870.
10. Guo, C., Zhao, C., Iravani, R. (2017) Impact of phase-locked loop on small-signal dynamics of the line commutated converter-based high-voltage direct-current station. IET Generation, Transmission \& Distribution. 11, 5: 1311-1318.

11. Karawita, C., Annakkage, U.D. (2009) Multi-Infeed HVDC Interaction Studies Using Small-Signal Stability Assessment. IEEE Transactions on Power Delivery. 24, 2: 910-918.

12. Zheng, A., Guo, C., Cui, P., Jiang, W., Zhao, C. (2019) Comparative Study on Small-Signal Stability of LCC-HVDC System With Different Control Strategies at the Inverter Station. IEEE Access. 7: 34946-34953. 